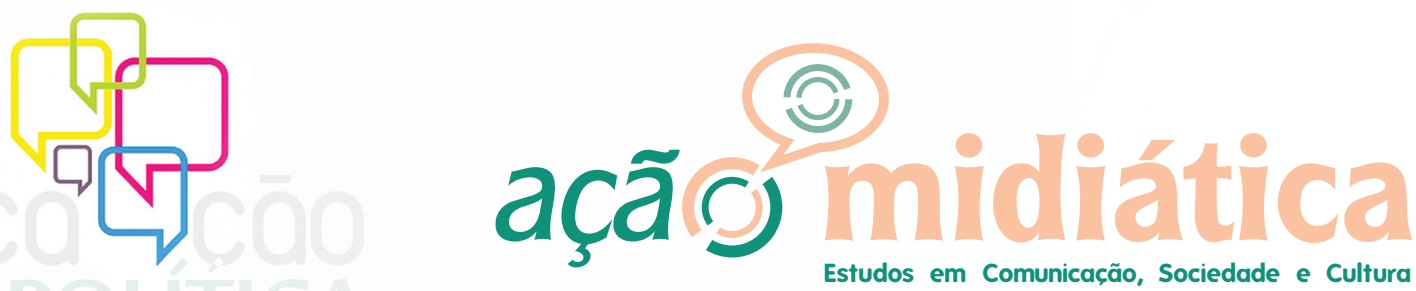

Estudos em Comunicação, Sociedade e Cultura

N. 6 | Ano 2013

Universidade Federal do Paraná I Programa de Pós-Graduação em Comunicação

\title{
Inclusão digital e governo eletrônico no Brasil: após 20 anos, muitos desafios ${ }^{1}$
}

Digital inclusion and e-government in Brazil: after 20 years, many challenges

La inclusión digital y el gobierno electrónico en Brasil: Después de 20 años, muchos retos

\section{Maria Lúcia BECKER²}

\begin{abstract}
RESUMO
O artigo tem como proposta enfocar os vinte anos (1993/94 a 2013/14) de iniciativas de inclusão digital e de projetos e programas de governo eletrônico no Brasil. Este rápido balanço busca contribuir para o debate sobre os desafios da comunicação pública de responsabilidade governamental, em sua relação com a cidadania e a democracia. Para isso, desenvolve-se com base em três procedimentos metodológicos: uma pesquisa documental, uma revisão de literatura e a construção e análise de séries históricas de dados selecionados dentro da base disponibilizada pelo Centro de Estudos sobre as Tecnologias da Informação e da Comunicação (CETIC.Br).
\end{abstract}

Palavras-chave: Cidadania; Comunicação Pública; Inclusão Digital; Democracia; Governo Eletrônico.

\begin{abstract}
The paper has the objective of examining the twenty years (from 1993/94 to 2013/14) of digital inclusion initiatives and projects and e-government programs in Brazil. This brief assessment seeks to contribute to the debate on the challenges faced by public communication of governmental responsibility, in relation to citizenship and democracy. The paper's argument is developed using three instruments: a documentary research, a literature review and the construction and analysis of historical series of selected data from the data base provided by the Center for the Study of Information Technology and Communication (CETIC. Br).
\end{abstract}

Keywords: Citizenship; Public Communication; Digital Inclusion; Democracy; Electronic Government.

\section{RESUMEN}

El artículo tiene por objeto estudiar los veinte años (1993/94 a 2013/14) de iniciativas de inclusión digital y de proyectos y programas de gobierno electrónico en Brasil. Esta rápida evaluación busca contribuir al debate sobre los retos de la comunicación pública bajo la responsabilidad gubernamental, en su relación con la ciudadanía y la democracia. Se desarrolla sobre la base de tres instrumentos: una investigación documental, una revisión de la literatura y la construcción y el análisis de series históricas con datos seleccionados dentro de la base de datos proporcionada por el Centro de Estudios de Tecnologías de la Información y la Comunicación (CETIC. Br).

Palabras clave: Ciudadanía; Comunicación Pública; Inclusión Digital; Democracia; Gobierno Electrónico.

1 Trabalho apresentado à sexta edição da Revista Ação Midiática - Estudos em Comunicação, Sociedade e Cultura, publicação ligada ao Programa de Pós-Graduação em Comunicação, da Universidade Federal do Paraná.

2 Jornalista. Mestre em Multimeios pela Universidade Estadual de Campinas (Unicamp). Doutora em Ciências da Comunicação pela Universidade de São Paulo (USP). Professora do Curso de Jornalismo e do Mestrado em Jornalismo da UEPG. E-mail: marialuciabecker@yahoo.com.br 


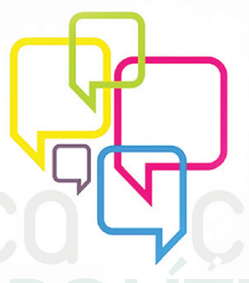

açãơ mididiática

N. 6 | Ano 2013

Universidade Federal do Paraná | Programa de Pós-Graduação em Comunicação

\section{Introdução}

Em 1993, Rodrigo Baggio criou o BBS 3 Jovem Link com o objetivo de construir "uma ponte digital promotora de uma integração social entre jovens ricos e pobres" (BAGGIO, 2005). Rapidamente a rede Jovem Link ganhou centenas de usuários, mas, para decepção de seu idealizador, uma verificação do perfil dos jovens conectados revelou que todos eram das classes A e B. "Percebi que os jovens de baixa renda não estavam conectados porque não tinham acesso a computadores. Em janeiro de 94 criei a primeira campanha de doação de computadores da América Latina, a Informática para Todos”. De acordo com Baggio (2005), foram convidados jovens do morro Dona Marta, favela próxima ao Ibase, ${ }^{4}$ para a reciclagem dos computadores usados recebidos por meio da campanha, que, em seguida, eram doados para as comunidades de baixa renda.

Estas foram ações pioneiras de inclusão digital no Brasil, num momento em que o uso da internet ainda não tinha sido aberto para a sociedade - havia apenas a Rede Nacional de Pesquisa (RNP), lançada em 1990, com uso exclusivo de professores, estudantes e funcionários de universidades e instituições de pesquisa. Nos 20 anos que se seguiram, inúmeros outros projetos e programas foram realizados por iniciativa de entidades da sociedade civil, dos governos (federal, estaduais e municipais) e de empresas. ${ }^{5}$

Apesar disso, as pesquisas realizadas pelo CETIC. $\mathrm{Br}^{6}$ revelam que o percentual de usuários de internet pertencentes às classes D/E se estabilizou em 13\% ou 14\%, mantendose inalterado no período de 2007 a 2012. Da mesma forma, chama a atenção o fato de a proporção de usuários de governo eletrônico situados nas classes $\mathrm{D} / \mathrm{E}$ ficar entre 4\% e 7\% e também não apresentar elevação entre 2007 e 2012, o mesmo acontecendo em relação ao conjunto de brasileiros que possui nível de escolaridade menor ou igual ao ensino fundamental completo (metade da população, segundo o Censo/2010), cujo percentual fica entre $10 \%$ e $12 \%$.

Estaria, então, esgotado nestes patamares o potencial de inclusão digital da população brasileira? Ou o problema é a falta de políticas públicas para a área, motivada pela percepção da

3 Bulletin Board System: sistema constituído por um computador pessoal que executa um software de painel de mensagens eletrônicas, ligado a uma linha telefônica e a um modem. Depois de ligar o modem ao computador e à linha telefônica e de dar um nome à BBS, o sistema funciona como um mural ou quadro de avisos, funcionando como a página inicial de um perfil no facebook.

4 Instituto Brasileiro de Análises Sociais e Econômicas, organização não-governamental pioneira no Brasil em ações de conexão à internet. Entre outras iniciativas, em 1989, com o apoio do Programa das Nações Unidas para o Desenvolvimento (Pnud), o Ibase lançou o Alternex, primeiro provedor brasileiro a possibilitar o acesso de pessoas físicas à internet. Com este provedor, o Ibase instalou uma rede de computadores na Eco-92 (Conferência das Nações Unidas sobre Meio Ambiente e Desenvolvimento). "Em 1994, o Alternex operava o primeiro servidor WWW do país fora da comunidade acadêmica". Para mais informações, cf. http://www.ibase.br/pt/

5 Um levantamento de projetos locais, regionais e nacionais pode ser encontrado em LEMOS, 2007, p. 18-30.

6 O Centro de Estudos sobre as Tecnologias da Informação e da Comunicação (CETIC.Br) é um departamento do Núcleo de Informação e Coordenação do Ponto BR (NIC.br), que pertence ao Comitê Gestor de Internet (CGI). 


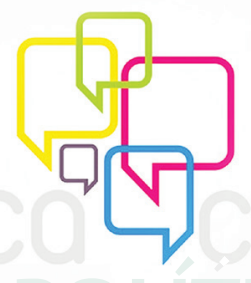

açãô I0 mididiática

Universidade Federal do Paraná | Programa de Pós-Graduação em Comunicação

inclusão digital como uma questão menor? Pode-se reconhecer como democrático um país com governos eletrônicos de acesso restrito às camadas superiores da pirâmide socioeconômica?

Com o objetivo de refletir sobre questões como estas, este artigo tem como base, além da pesquisa bibliográfica, também uma pesquisa documental e a construção de séries históricas com dados selecionados dos levantamentos publicados pelo CETIC.Br. Faz também uma sistematização do processo de construção da relação conceitual e histórica entre governo eletrônico e inclusão digital, apontando para exigências de caráter ético.

\section{Muitos jovens, poucos pobres}

O binômio inclusão/exclusão digital tornou-se de uso corrente desde o início da década de 1990 no Brasil, quando as mudanças relacionadas ao processo de globalização articulado com o de informatização definem o perfil do que passa a ser entendido como sociedade tecnológica global. Neste sentido, entre os tantos "feitos" da tecnologia digital, deve ser acrescentado mais um: o de chamar a atenção da sociedade para a existência de pobres - da sociedade como um todo, inclusive das próprias pessoas em situação de pobreza, que passaram a ter mais um motivo para se indignar e questionar a desigualdade social. Isto porque a cidadania (pertencimento/ participação) na sociedade atual não se faz apenas com computadores conectados à internet, depende também e principalmente da configuração da outra parte, aquela que fica do lado de cá da tela.

No livro "Inclusão digital e cidadania: as possibilidades e ilusões da 'solução' tecnológica”, Becker (2009, p. 78-79) indica cinco conjuntos de elementos que compõem o conceito de inclusão digital: 1) infra-estrutura e equipamentos (meios de processamento de informações e de comunicação); 2) instrumental cognitivo (não só alfabetização digital, mas também a velocidade operatória no uso de software e aplicativos, assim como "qualificação para localização e tratamento da informação dispersa" e domínio do chamado "inglês de computador;"); 3) constituição de tele-existência (ampliação - em quantidade e qualidade - da circulação em rede das informações, saberes e criações dos diferentes grupos, organizações e comunidades locais; 4) acesso público e gratuito dentro da rede (aos conteúdos necessários ao exercício da cidadania); e 5) transformação/desenvolvimento de tecnologia (de forma a adequar não as pessoas às tecnologias e sim as tecnologias às demandas pessoais e coletivas existentes nos diferentes segmentos da sociedade).

Verificar as implicações destes elementos no processo de inclusão e não-inclusão digital no Brasil contribui para a compreensão dos 20 anos em foco e das tendências colocadas. É o que se pretende no decorrer da apresentação de dados feita a seguir. 


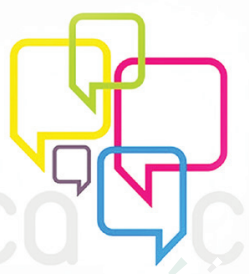

ação minidiáticaca

N. 6 | Ano 2013

Universidade Federal do Paraná I Programa de Pós-Graduação em Comunicação

Em 2012, o número de usuários da internet $^{7}$ no Brasil superou, pela primeira vez, o número de não-usuários. $\mathrm{O}$ país passou a ter $49 \%$ de usuários ( 80,9 milhões) contra $45 \%$ (75 milhões) de pessoas com 10 anos ou mais que nunca acessaram a internet. Os números são da pesquisa “TIC Domicílios e Usuários 2012”, feita pelo CETIC.Br no período de outubro/2012 a fevereiro/2013.

Em 2008, apenas 34\% da população usava a internet. Os 15 pontos percentuais de aumento no período até 2012, todavia, distribuem-se de forma desigual entre as áreas urbana e rural.

\begin{tabular}{|c|c|c|c|c|c|c|c|c|}
\hline & 2005 & 2006 & 2007 & 2008 & 2009 & 2010 & 2011 & 2012 \\
\hline Urbana & - & - & 40 & 38 & 43 & 45 & 50 & 54 \\
\hline Rural & - & - & - & 15 & 18 & 16 & 18 & 18 \\
\hline Total & 24 & 28 & - & 34 & 39 & 41 & 45 & 49 \\
\hline
\end{tabular}

Tabela 1: Série histórica 2005-2012. Proporção de usuários de internet, ${ }^{8}$ por ano. Percentual sobre a população urbana, rural e total. ${ }^{9}$ Fonte: Elaboração própria com dados do CETIC.br (<http://www.cetic.br/publicacoes/>)

Como se pode observar na tabela, há um aumento contínuo da diferença entre a proporção das áreas urbanas e rurais. Em 2008, essa diferença é de 23 pontos; em 2009, de 25; em 2010, de 29; em 2011, de 32; e, em 2012, de 36 pontos. Sobre este aumento, a análise feita pelo CETIC. Br (2012, p. 159) diz que "as razões podem estar relacionadas à baixa atratividade do mercado para os provedores de acesso à rede e aos elevados investimentos para levar a Internet para áreas rurais". E aponta a "necessidade de políticas públicas especificamente voltadas à inclusão dessa população".

A recomendação faz sentido diante da condução governamental de algumas iniciativas na área da inclusão digital, entre as quais duas merecem destaque: o Fundo de Universalização dos Serviços de Telecomunicações (Fust) e o Governo Eletrônico - Serviço de Atendimento ao Cidadão (Gesac).

O Fust tem sido objeto de polêmicas, esperanças e desesperanças desde antes de sua criação, quando o projeto foi formulado "como um catalisador na diminuição da distância entre aqueles indivíduos do topo da pirâmide social e os da sua parte mais inferior" (QUEIROZ, 2010, p. 16). Debatido no bojo dos embates sobre a privatização do sistema Telebrás, nos anos 1997-98, enfrentou resistências que postergaram sua aprovação até o ano 2000, passando a sua

7 O CETIC.Br considera usuário todo indivíduo que acessou a internet nos últimos três meses. Segundo a pesquisa de 2012, $70 \%$ dos usuários urbanos e $43 \%$ dos rurais acessam diariamente, enquanto $22 \%$ dos usuários urbanos e $37 \%$ dos rurais acessam pelo menos uma vez por semana. Cf. $<$ http://www.cetic.br/publicacoes/2012/tic-domicilios-2012.pdf $>$

8 Neste trabalho, em todas as tabelas, adota-se o conceito de usuário estabelecido pelo CETIC.Br, ou seja, são considerados usuários apenas os indivíduos que acessaram a internet nos últimos três meses em relação à data da entrevista. O CETIC. Br também traz os dados de indivíduos que acessaram nos últimos 12 meses e há mais de 12 meses.

9 A tabela não inclui dados sobre população urbana e rural nos anos de 2005 e 2006, assim como população rural e total em 2007, porque não constam nas pesquisas do CETIC.Br devido à metodologia de coleta de dados adotada na época. 


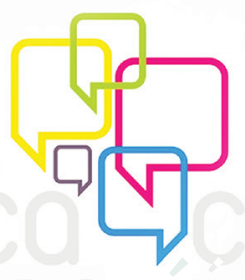

ação midiáática

N. 6 | Ano 2013

Universidade Federal do Paraná | Programa de Pós-Graduação em Comunicação

cobrança a ser feita só a partir de 2001.

De acordo com o decreto que regulamentou a sua criação (DECRETO No $3.624 \ldots$.., 2000) o fundo é constituído basicamente por quatro tipos de receitas: 1) recursos previstos na lei orçamentária da União; 2) 50\% de todos os recursos recebidos pelo governo na área de telecomunicações a título de pagamentos por outorgas e de pagamentos pela expedição de autorização de serviço, incluindo multas e indenizações, assim como das quantias recebidas pela aprovação de laudos de ensaio de produtos e pela prestação de serviços técnicos por órgãos da Agência Nacional de Telecomunicações (Anatel) - tudo isso até o limite máximo anual de setecentos milhões de reais; 3) recursos provenientes da cobrança feita pela Anatel para a transferência de concessão, de permissão ou de autorização de serviço de telecomunicações ou de uso de radiofrequência; e 4) contribuição de um por cento sobre a receita operacional bruta das empresas de telefonia, excluindo-se os impostos. De 2001 a 2010, o Fust amealhou cerca de R\$ 9,6 bilhões (BERBERT, 2011).

O uso dos recursos para programas de inclusão digital está previsto nos incisos IV, V, VI e VII do Art. $13^{\circ}$ do Decreto que regulamentou o Fust. Mas a operacionalização deste uso fica na dependência do cumprimento do Art. $2^{\circ}$, que estabelece: "Cabe ao Ministério das Comunicações formular as políticas, as diretrizes gerais e as prioridades que orientarão as aplicações do Fust, bem como definir os programas, os projetos e as atividades financiados com recursos do Fundo" (DECRETO No 3.624 ..., 2000). Como isto não estava sendo feito, em 2005, o Tribunal de Contas da União (TCU) realizou uma auditoria para verificar as razões da não aplicação dos recursos. Concluiu, em síntese, que:

(...) não existem políticas públicas, diretrizes gerais e prioridades no âmbito do Ministério das Comunicações para orientar a aplicação dos recursos do FUST; não há uma política integrada e nem prioridade para as iniciativas de inclusão digital do Poder Executivo Federal; houve inconsistência entre a Anatel e o Ministério das Comunicações na discussão do Serviço de Comunicações Digitais -SCD; e, por fim, o arcabouço legislativo que rege o FUST não impede a aplicação dos seus recursos (QUEIROZ, 2010, p. 19).

Apesar das recomendações feitas pelo TCU na ocasião, até o final de 2008, os recursos do FUST haviam sido aplicados uma única vez: no "Projeto de Atendimento a Instituições de Apoio a Pessoas com Deficiência Auditiva" (QUEIROZ, 2010, p. 19). Pressionado por parlamentares e por organizações da sociedade civil ${ }^{10}$ durante mais de dez anos, o MiniCom avançou, em 2013, do argumento de que "a legislação prevê como destinação prioritária a universalização da telefonia fixa" para a posição de defesa do uso dos recursos para o programa

10 Cf., por exemplo, "Proposta do Intervozes para uso do fust", em $<$ http://intervozes.org.br/publicacoes/proposta-do-intervozes-para-uso-do-fust/> 


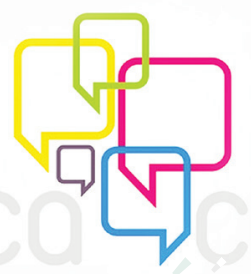

açã

Estudos em Comunicação, Sociedade e Cultura

N. 6 | Ano 2013

Universidade Federal do Paraná | Programa de Pós-Graduação em Comunicação

Cidades Digitais (HAJE, 2013). Desde que começaram a ser arrecadados, os recursos têm sido usados para gerar ou aumentar o superávit primário. ${ }^{11}$

Já o Governo Eletrônico - Serviço de Atendimento ao Cidadão (Gesac) foi criado em 2002 com o "objetivo de promover a inclusão digital e social, bem como para incentivar ações de governo eletrônico para a população". De acordo com a página do programa (<http://www. gesac.gov.br/>), o Gesac "é direcionado, prioritariamente, para comunidades em estado de vulnerabilidade social, em todos os estados brasileiros, privilegiando as cidades do interior, sem telefonia fixa e de difícil acesso». E o relatório da pesquisa de avaliação do programa indicava a existência, em 2008, de 3.570 Pontos Gesac, número que, segundo o documento, teria aumentado em 2010 para 11.500 (GESAC, 2010, p. 9). Mas à pequena quantidade (o país tem 5.565 municípios) junta-se a baixa qualidade: o Gesac funcionou até 2012 por meio de fornecimento das conexões via satélite por empresas que entregam uma velocidade de, no máximo, $40 \mathrm{kbps}$, ou seja, uma velocidade menor do que a oferecida pela conexão discada (GROSSMANN, 30/08/2013).

Do ponto de vista das classes sociais, também há uma distribuição desigual dos 15 pontos percentuais de aumento no número de usuários de internet verificado de 2008 a 2012. Na classe A, o percentual subiu de $89 \%$, em 2008 , para $94 \%$, em 2012. A classe B passou de $68 \%$ para $80 \%$ no mesmo período. Na classe C, houve um crescimento de $38 \%$ para $47 \%$. Já as classes D/E continuaram praticamente com o mesmo percentual de usuários: 13\% (2008), 14\% (2009), 13\% (2010), 13\% (2011) e 14\% (2012). A mesma pesquisa, no entanto, revela que, em 2005 e 2006, o percentual de pessoas das classes D/E que usavam a internet ficava em torno de $8 \%$ a $9 \%$. Ou seja, os dados indicam um crescimento no início da pesquisa que não continua no período de 2008 a 2012.

\begin{tabular}{|c|c|c|c|c|c|c|c|c|}
\hline & 2005 & 2006 & $2007^{1}$ & 2008 & 2009 & 2010 & 2011 & 2012 \\
\hline $\mathrm{A}$ & 85 & 93 & - & 89 & 85 & 84 & 92 & 94 \\
\hline $\mathrm{B}$ & 63 & 67 & - & 68 & 72 & 73 & 77 & 80 \\
\hline $\mathrm{C}$ & 27 & 31 & - & 38 & 42 & 42 & 45 & 47 \\
\hline $\mathrm{D} / \mathrm{E}$ & 8 & 9 & - & 13 & 14 & 13 & 14 & 14 \\
\hline
\end{tabular}

Tabela 2: Série histórica 2005-2012. Proporção de usuários de internet, por ano ${ }^{12}$ e classe social - Percentual sobre o total da população. Fonte: Elaboração própria com dados do CETIC.br (<http://www.cetic.br/publicacoes $/>)$

Diante disso, uma observação fundamental é que houve um crescimento constante do número de usuários na classe $\mathrm{C}$ e, para uma análise desse fato, vale lembrar que houve, no

11 Diferença positiva entre receitas e despesas do governo. Quanto mais alto o superávit primário, maior é a confiança no governo quanto ao pagamento dos juros da dívida pública, aumentando a demanda por títulos da dívida, o que permite uma queda da taxa real de juros da economia, que, por sua vez, faz crescer o Produto Interno Bruto (PIB).

12 Como até 2007, o CETIC.Br divulgou dados fracionados, para efeito de padronização da tabela, os números dos anos 2005 e 2006 foram aqui arredondados para cima ou para baixo, de acordo com as frações acima ou abaixo de 0,50. 


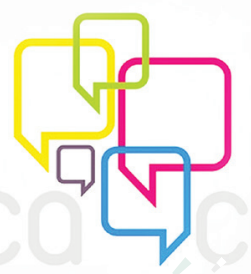

período, também um aumento do número de pessoas nesta classe. De acordo com a pesquisa Observador Brasil-2012 (CETELEM BGN, 2012, p. 20-23) sobre o perfil do consumidor, em 2011 a classe $C$ passou a representar $54 \%$ da população, mudança que ocorreu no período de 2007 a 2011 (em 2006, a classe C tinha 36\% e as D/E 46\%; em 2011, a D/E já significava apenas 24\%). Assim, considerando que, na metodologia da pesquisa CETIC.Br, a definição da amostra segue a distribuição da população brasileira, com base nos dados do Censo de 2010 e da PNAD de 2011 e também acompanha o Critério Brasil da Abep ${ }^{13}$ para definição das classes (metade da amostra pesquisada na pesquisa TIC Domicílios 2012 pertence à classe C, 25\% são classificados como classe B, 23\% como classe DE, e 3\% como classe A), inferese que, tanto o aumento da inclusão digital na classe $\mathrm{C}$ quanto a estabilização do aumento nas classes $\mathrm{D} / \mathrm{E}$ tem como fator determinante a mobilidade social relacionada à política econômica adotada no período, caracterizada, entre outros aspectos, por uma expansão geral do consumo.

Quanto à não inclusão digital de mais de $80 \%$ das classes $\mathrm{D} / \mathrm{E}$ e das populações das áreas rurais, o primeiro motivo a ser considerado é a falta de acesso à infra-estrutura de rede e equipamentos. Mas não é o único. Além da frustração causada pela navegação lenta e precária e das dificuldades para frequentar um posto de acesso público à internet (na zona rural, devido às distâncias e, nas periferias urbanas, devido ao tempo/horários a que estão presos os trabalhadores), há desafios cuja superação depende de um grau de atenção ainda não obtido pela maioria da população rural ${ }^{14} \mathrm{e}$ das periferias urbanas nesses vinte anos de internet no país: o esforço e persistência necessários para obter resultados na busca de conteúdos por parte de quem tem letramento incipiente; a falta de familiaridade e de identificação, devido à quase inexistência de conteúdos que expressam as especificidades socioculturais do grupo/ comunidade de que faz parte; e o distanciamento tecnológico (das interfaces, aplicativos) em relação às necessidades e interesses do/a candidato/a a usuário/a.

Ao mesmo tempo, os números do uso da internet de acordo com a faixa etária demonstram um crescimento gradativo e permanente de 2005 a 2012 (Tabela 3), sendo a mesma tendência observada na proporção segundo o grau de escolaridade (Tabela 4).

13 Associação Brasileira de Empresas de Pesquisa. O Critério de Classificação Econômica Brasil (CCEB) estabelece um sistema de pontuação de acordo com a posse de eletrodomésticos (televisor em cores, geladeira, freezer, rádio, videocassete e/ou DVD, máquina de lavar, excluindo tanquinho), número de banheiros (privativos do domicílio, excluindo banheiros coletivos), número de automóveis (excluindo veículos de uso profissional e também os de uso misto, ou seja, profissional e lazer), número de empregados domésticos (apenas mensalistas) e o grau de escolaridade "do chefe da família". Para mais detalhes, cf. http://www.abep.org/novo/Content.aspx?SectionID=84

14 Toma-se como referência aqui principalmente as pessoas situadas nas classes D/E, que, dadas as condições socioeconômicas, acabam reféns do que Milton Santos chama de "imobilidade relativa", ou seja, ficam "praticamente isolados ali onde vivem” (SANTOS, apud BECKER, p. 172). 


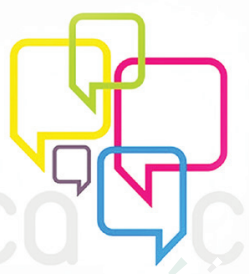

ação

Estudos em Comunicação, Sociedade e Cultura N. 6 | Ano 2013

Universidade Federal do Paraná I Programa de Pós-Graduação em Comunicação

\begin{tabular}{|c|c|c|c|c|c|c|c|}
\hline & 2005 & 2006 & 2008 & 2009 & 2010 & 2011 & 2012 \\
\hline $10-15$ & 30 & 38 & 53 & 63 & 65 & 67 & 70 \\
\hline $16-24$ & 46 & 49 & 61 & 68 & 64 & 70 & 74 \\
\hline $25-34$ & 26 & 35 & 41 & 51 & 52 & 56 & 62 \\
\hline $35-44$ & 20 & 21 & 26 & 29 & 33 & 41 & 46 \\
\hline $45-59$ & 15 & 11 & 13 & 16 & 20 & 25 & 31 \\
\hline 60 ou + & 4 & 3 & 2 & 5 & 5 & 9 & 8 \\
\hline Brasil & 24 & 28 & 34 & 39 & 41 & 45 & 49 \\
\hline
\end{tabular}

Tabela 3: Série histórica 2005-2012. Proporção de indivíduos que acessam a internet, por ano, segundo a idade dos indivíduos ${ }^{15}$ - Percentual sobre o total da população. Fonte: Elaboração própria com dados do CETIC.br $(<$ http:// www.cetic.br/publicacoes/>)

\begin{tabular}{|c|c|c|c|c|c|c|c|}
\hline & 2005 & 2006 & 2008 & 2009 & 2010 & 2011 & 2012 \\
\hline Fundamental & 20 & 22 & 30 & 36 & 43 & 29 & 30 \\
\hline Médio & 45 & 42 & 53 & 60 & 58 & 68 & 72 \\
\hline Superior & 79 & 82 & 83 & 87 & 81 & 91 & 93 \\
\hline
\end{tabular}

Tabela 4: Série histórica 2005-2012. Proporção de indivíduos que acessam a internet, por ano, segundo o grau de escolaridade - Percentual sobre o total da população. Fonte: Elaboração própria com dados do CETIC.br (<http:// www.cetic.br/publicacoes/>)

Os dados mostram que há um crescimento contínuo no número de usuários de internet no período de 2005 a 2012, principalmente nas três primeiras faixas etárias, com aumento acima da média nacional: 40 pontos percentuais, dos 10 a 15 anos; 28 pontos, dos 16 a 24 anos; e 36 pontos, dos 25 a 34 anos. No recorte pelo grau de instrução, o crescimento maior se verifica entre a população com ensino médio, onde a variação chega aos 27 pontos percentuais no período.

Além da conhecida sedução exercida pelas novas tecnologias sobre adolescentes e jovens, os números refletem o avanço das políticas públicas na área de informatização da rede escolar. De acordo com dados do Ministério da Educação, no ensino médio, 95,6\% dos alunos matriculados estão em estabelecimentos com acesso à internet e 95,1\% em estabelecimentos com laboratório de informática. Já no ensino fundamental, 79,5\% das matrículas estão em escolas com acesso à internet e 76,9\% dos estudantes têm acesso a laboratório de informática (TOCARNIA, 2013).

Para uma reflexão sobre a busca de universalização do acesso, entretanto, tão importante quanto observar os números da inclusão é (re)conhecer quantitativa e qualitativamente a nãoinclusão. De acordo com a Pesquisa Nacional por Amostra de Domicílios (PNAD) - 2011-

15 Aqui, novamente, os dados do ano de 2007 foram suprimidos porque, segundo o CETIC.Br, referem-se apenas à população urbana. A inclusão destes números traria um desvio na série histórica. Cf. $<$ http://op.ceptro.br/cgi-bin/cetic/tic-2007.pdf $>$ 

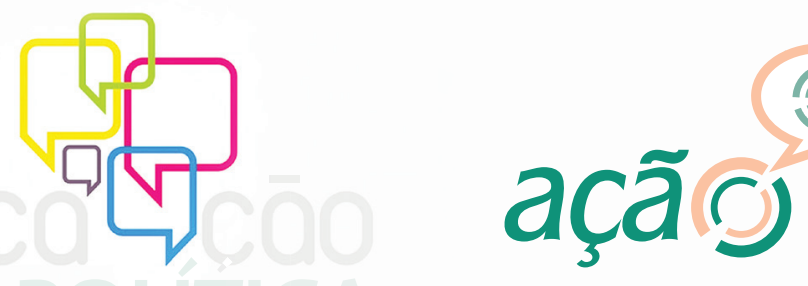

Estudos em Comunicação, Sociedade e Cultura

N. 6 | Ano 2013

Universidade Federal do Paraná I Programa de Pós-Graduação em Comunicação

2012, entre os brasileiros com mais de 10 anos de idade, 9\% têm menos de um ano de estudo, $11 \%$ têm de 1 a 3 anos, 26,5\% têm de 4 a 7 anos e 17,4\% têm de 8 a 10 anos de escolaridade. Isto significa que quase a metade dos brasileiros não terminou o ensino fundamental. Destes, cerca de $70 \%$ não são usuários de internet.

Quanto aos jovens e adolescentes, a questão é: quem são os 30\% ainda desconectados? $\mathrm{E}$ a resposta "certamente os pertencentes às classes $\mathrm{D} / \mathrm{E}$ ” traz outra questão: a sociedade brasileira quer enfrentar os desafios da inclusão digital (os mesmos colocados desde 1993/94), ou está à espera de que o crescimento vegetativo resolva o problema, mesmo que, assim, a universalização do acesso ainda demore pelo menos cinco décadas?

\section{Inclusão digital e governo eletrônico}

A constituição do conceito de governo eletrônico no Brasil não se deu no ato de assinatura do decreto que o instituiu, como programa, no ano 2000. Ao contrário, sua construção socialhistórica vem acontecendo desde 1994/1995, quando o uso da internet passa a ser possível à sociedade por meio da multiplicação de provedores de acesso em diversos locais do país. Desde então, a ideia de um governo eficiente, com serviços acessíveis sete dias por semana, vinte e quatro horas por dia, junto com a ideia de finalmente a sociedade poder ver respeitado o seu direito à informação, vem se fazendo acompanhar do embate ético da garantia de acesso para todos, o que significa, inclusão digital como direito dos cidadãos e dever do Estado.

No governo eletrônico, segundo Martins, as atividades podem ser classificadas em três áreas: 1) serviços de uso direto por parte dos cidadãos e empresas; 2) serviços visando à melhoria da eficiência da máquina pública; e 3) recursos para o exercício da cidadania. Neste último caso, "os cidadãos passam a ter condições de acompanhar, participar e controlar as ações do governo de maneira mais direta e próxima da realização, além de passar a contar com recursos da tecnologia da informação no exercício da democracia" (MARTINS, 2004, p. 17). O Livro Verde, publicado pelo Ministério da Ciência e Tecnologia logo após a criação do Programa Sociedade da Informação (em 15/12/1999) já reconhecia que, "no novo paradigma gerado pela sociedade da informação, a universalização dos serviços de informação e comunicação é condição fundamental, ainda que não exclusiva, para a inserção dos indivíduos como cidadãos" (LIVRO VERDE, 2000, p. 31).

As primeiras iniciativas concretas de e-gov no Brasil surgem em meados dos anos 1990, entre elas o Portal Rede Governo (atualmente transformado em Guia de Serviços Públicos do Governo Federal) e a ReceitaNet, que, em 1996, passou a fazer a validação e recebimento de declarações de impostos e contribuições federais. Ao mesmo tempo, passam a fazer parte dos debates, nos diversos níveis de governo, as preocupações e propostas relacionadas à inclusão digital. Em Curitiba (PR), por exemplo, em 1995, a prefeitura municipal instala um ponto de 

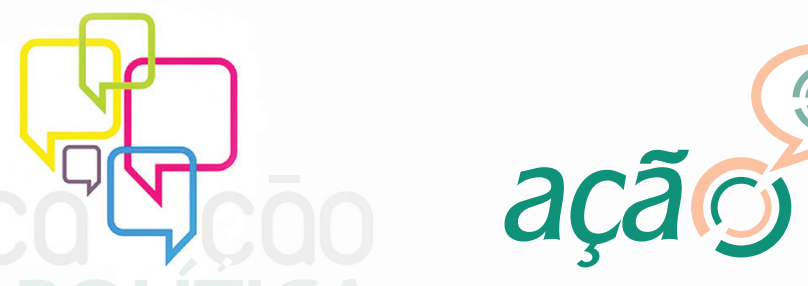

Estudos em Comunicação, Sociedade e Cultura

N. 6 | Ano 2013

Universidade Federal do Paraná | Programa de Pós-Graduação em Comunicação

acesso público e gratuito à internet na biblioteca chamada "Farol das Cidades", onde também coloca totens para o cidadão acessar serviços públicos disponíveis online.

O decreto presidencial que institui o Governo Eletrônico no Brasil, em 03/04/2000, cria o Grupo de Trabalho em Tecnologia da Informação (GTTI), cujo relatório final enfatiza: “a universalização dos serviços tem como diretriz estimular o acesso à Internet seja individual, público, ou ainda coletivo e comunitário". De acordo com o documento "a meta é colocar o governo ao alcance de todos, ampliando a transparência das suas ações, e incrementando a participação cidadã" (PROPOSTA DE ..., 2000). No ano 2000, o Portal Rede Governo oferecia 629 serviços e 3.500 informações. Um levantamento realizado pelo Comitê Executivo do Governo Eletrônico, em 2002, identifica 557 projetos e iniciativas de e-gov em todo o país (2 ANOS DE ..., 2002, p. 11).

Com a Lei de Responsabilidade Fiscal (LRF - sancionada em 5/05/2000), a relação entre governo eletrônico e inclusão digital se intensifica. Dos quatro eixos em que se estrutura a LRF, dois se baseiam diretamente na publicização: Transparência e Controle (os outros dois são Planejamento e Responsabilização). De acordo com a lei, a transparência se concretiza com a divulgação ampla de quatro relatórios de acompanhamento da gestão fiscal que permitam identificar receitas e despesas. Já o controle depende da transparência e da qualidade das informações (KHAIR, 2000, p. 14). Como a LRF exige a publicação dos relatórios e também a sua disponibilização na internet, municípios e estados passaram a cumprir a lei apenas com a criação de um sítio na internet, de forma a ter o menor dispêndio possível de recursos financeiros.

No balanço das metas e resultados do programa de Governo Eletrônico feito em 2002, o Comitê Executivo ressalta que "a política de Governo Eletrônico foi alçada à agenda prioritária do Governo Federal". Em relação à universalização do acesso à internet, no entanto, o balanço constata que "as metas estabelecidas foram demasiado ousadas e mesmo de inviável atingimento"; que o GESAC - Governo Eletrônico: Serviço de Atendimento ao Cidadão (projeto de implantação de terminais públicos) "teve sua implementação retardada em virtude de serem os recursos provenientes do FUST", tendo sido já contratada a instalação de 3.500 conjuntos de equipamentos "dos quais 800 ainda em 2002"; que o projeto de disseminação de Pontos Eletrônicos de Presença (que previa a instalação de 6 mil pontos até o final de 2002, abrangendo 2 mil municípios), não avançou, "devido ao corte de recursos orçamentários", sendo feita apenas a instalação de 80 pontos em órgãos da administração federal, "custeados por parceiros privados"; que, enfim, "os projetos para disseminação de terminais eletrônicos pretendiam a instalação de mais de 250 mil equipamentos, até o final de 2003, sob diversos formatos e arranjos institucionais, configurando meta demasiado otimista" (2 ANOS DE ..., 2002, p. 26-27).

Neste contexto, a lista de 16 "desafios futuros" apresentada no final do documento, traz 


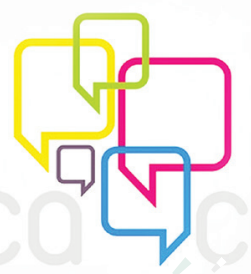

ação midiáática

N. 6 | Ano 2013

Universidade Federal do Paraná | Programa de Pós-Graduação em Comunicação

apenas um ponto (o último) relacionado à universalização do acesso à internet, com o seguinte texto: "consolidar e disseminar modelos de parceria com entidades da sociedade civil e com outros níveis de governo, para a implementação de projetos e operação de serviços, em particular aqueles voltados para a ampliação do acesso à Internet e para a transparência da ação governamental". Vale citar que, no entendimento do Comitê Executivo, o "patrocínio" por parte dos "altos dirigentes" faz parte do desafio número um a ser enfrentado pelo Governo Eletrônico (2 ANOS DE ..., 2002, p. 37-38).

Em 2003, um decreto presidencial cria oito "Comitês Técnicos" dentro do Comitê Executivo do Governo Eletrônico, sendo um deles o de Inclusão Digital. Os anos seguintes são marcados por ações no sentido da consolidação e aperfeiçoamento do Governo Eletrônico e da ampliação da inclusão digital, entre as quais:

2004 - criação do Departamento de Governo Eletrônico; lançamento da primeira versão da e-PING - Padrões de Interoperabilidade de Governo Eletrônico; ${ }^{16}$

2005 - lançamento do Modelo de Acessibilidade de Governo Eletrônico (e-MAG); regulamentação das compras governamentais, tornando obrigatório na Administração Pública Federal o uso do pregão, preferencialmente eletrônico;

2006 - lançamento do Portal da Inclusão Digital e da Metodologia de Indicadores e Métricas de Serviços de Governo Eletrônico; ${ }^{17}$

2007 - institucionalização do e-MAG, tornando obrigatório seu uso no âmbito do Sistema de Administração dos Recursos de Tecnologia da Informação (SISP);

2008 - lançamento de cartilhas com os "Padrões Brasil E-GOV", que reúnem recomendações de "boas práticas" e lançamento do Portal de Convênios para a realização de convênios e contratos de repasse com recursos da União;

2009 - criação do Comitê Gestor do Programa de Inclusão Digital (CGPID), sob coordenação da Casa Civil da Presidência da República e com a participação de oito ministérios;

2010 - lançamento do Plano Nacional de Banda Larga, tendo como objetivos, entre outros, promover a inclusão digital, ampliar os serviços de Governo Eletrônico, facilitar aos cidadãos o uso dos serviços do Estado e promover a capacitação da população para o uso das tecnologias de informação; ${ }^{18}$

16 A versão 2013 da e-PING pode ser baixada no site do Governo Eletrônico: $<\underline{\text { http://www.governoeletronico.gov.br/acoes-e }}$ -projetos/e-ping-padroes-de-interoperabilidade>

$17 \mathrm{O}$ arquivo dos Indicadores e Métricas para Avaliação de e-Serviços pode ser baixado em: $<\underline{\text { http://www.governoeletronico. }}$ gov.br/acoes-e-projetos/indicadores-e-metricas-para-avaliacao-de-e-servicos $>$

18 Dentro do objetivo de "massificar o acesso a serviços de conexão à Internet em banda larga", quando foi lançado o programa, a meta estabelecida foi de proporcionar o acesso à banda larga a 40 milhões de domicílios brasileiros até 2014 à velocidade de no mínimo 1 Mbps. Em 2013, com base em negociações com as operadoras, a meta foi definida como "oferta de banda larga no varejo de 1 Mbps a R\$35 nas localidades-sedes de todos os municípios até 2014" e cobertura por serviços de voz e dados em "área correspondente a um raio de $30 \mathrm{~km}$ a partir da localidade sede de todos os municípios brasileiros". Para mais detalhes sobre o desenvolvimento do PNBL, cf. Balanço 2010-2013, em: <http://www.mc.gov.br/editais-e-avisos/doc download/1419-balanco-2010-2013> 


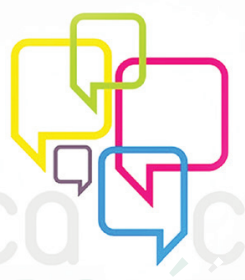

ação mididiática

N. 6 | Ano 2013

Universidade Federal do Paraná | Programa de Pós-Graduação em Comunicação

2011 - criação da Secretaria de Inclusão Digital (SID) do Ministério das Comunicações; Regulamentação do acesso a dados e informações detidas pelo governo, por meio da Lei de Acesso à Informação Pública, sancionada em 18/11/11; Instituição do Plano de Ação Nacional sobre Governo Aberto, com o objetivo de que "todos possam encontrar e utilizar os dados e as informações públicas", de forma a proporcionar "ao cidadão um melhor entendimento do governo, no acesso aos serviços públicos, no controle das contas públicas e na participação no planejamento e desenvolvimento das políticas públicas"; 19

2012 - lançamento do projeto-piloto das Cidades Digitais, com a seleção de 80 municípios para implantação do "modelo básico", que prevê: conexão entre os órgãos públicos; implantação de aplicativos de gestão para os setores financeiro, tributário, de saúde e educação; capacitação de servidores públicos no uso específico dos softwares e nas TICs; acesso da população aos serviços de governo eletrônico; e pontos de acesso público à internet em praças, rodoviárias e outros espaços;

2013 - inclusão do Cidades Digitais no Programa de Aceleração do Crescimento (PAC) e seleção de 262 municípios para a segunda etapa do programa.

A lista acima dá a impressão de que, se tudo não está resolvido, ao menos quanto ao período de 2003 a 2013 se poderia dizer que as ações e programas vêm caminhando no sentido de avanços sólidos e contínuos. Os dados referentes à utilização de governo eletrônico no Brasil, entretanto, mostram outra realidade.

De 2005 a 2011, o número de pessoas com ensino fundamental que utilizou governo eletrônico se manteve praticamente o mesmo, variando em percentuais que não ultrapassaram os 12\% (Tabela 5). Enquanto isso, o número de usuários de e-gov entre aqueles que completaram o ensino médio variou de $19 \%$ a $48 \%$. Da mesma forma, o percentual entre os que têm ensino superior cresceu, com algumas oscilações, de 54\% até $77 \%$. Considerando que, como já citado, metade dos brasileiros têm menos do que o Ensino Fundamental, chama a atenção o fato de apenas 10 a 12\% desta utilizar governo eletrônico (cerca de 10 a 12 milhões de brasileiros, pela estimativa da população em 2011). ${ }^{20}$ Mais grave: trata-se de um percentual que se mostra estável - sem crescimento no período de 2007 a 2011.

19 Para mais informações sobre o desenvolvimento do governo eletrônico e sobre o Portal Brasileiro de Dados Abertos, cf.

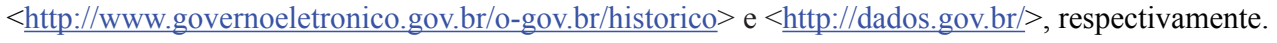

20 Estimativa divulgada pelo IBGE em agosto/2011. Cf. http://saladeimprensa.ibge.gov.br/noticias?view=noticia\&id=1\&bus $\underline{\mathrm{ca}=1 \text { \&idnoticia }=1961}$ 


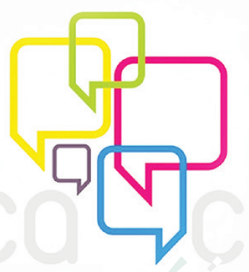

açãô Imidiática

N. 6 | Ano 2013

Universidade Federal do Paraná I Programa de Pós-Graduação em Comunicação

\begin{tabular}{|c|c|c|c|c|c|c|c|}
\hline & 2005 & 2006 & 2007 & 2008 & 2009 & 2010 & 2011 \\
\hline Fundamental & 8 & 4 & 10 & 10 & 12 & 10 & 10 \\
\hline Médio & 28 & 19 & 38 & 38 & 43 & 35 & 48 \\
\hline Superior & 55 & 54 & 71 & 71 & 78 & 66 & 77 \\
\hline
\end{tabular}

Tabela 5: Série histórica 2005-2011. Proporção de usuários de governo eletrônico ${ }^{21}$ por ano, segundo o grau de escolaridade - Percentual sobre o total da população. Fonte: Elaboração própria com dados selecionados da pesquisa TIC-Domicílios (<http://www.cetic.br/publicacoes/>)

Quanto ao ano de 2012, os dados mostram que $45 \%$ dos usuários de internet ${ }^{22}$ que têm até o ensino fundamental utilizaram o governo eletrônico nos últimos 12 meses (Tabela 7); ou seja: de todos os brasileiros que têm escolaridade igual ou menor que o ensino fundamental (cerca de 97 milhões de pessoas, pela estimativa populacional de 2012), ${ }^{23} 30 \%$ são usuários de internet (cerca de 29 milhões), e, destes, menos da metade (45\%, cerca de 13 milhões) utiliza o governo eletrônico, o que agrava o quadro apresentado acima, revelando que a tendência de não crescimento se mantém. Para efeito de comparação, entre os usuários de internet que têm ensino superior, $85 \%$ utilizam governo eletrônico.

Na proporção segundo a classe social, a diferença entre o percentual mais baixo e o mais alto, no período de 2005 a 2011, resulta em 29 pontos na classe A, 26 pontos na B, 15 pontos na $\mathrm{C}$ e 5 nas classes D/E. No ano de 2012, a tendência se mantém: sendo em torno de $25 \%$ os brasileiros das classes $\mathrm{D} / \mathrm{E}$ (aproximados 50 milhões) e sendo 14\% a proporção de usuários de internet nestas classes (cerca de 7 milhões), a identificação de 48\% de usuários de e-gov situados nas classes $\mathrm{D} / \mathrm{E}$ revela um número próximo de 3.360 .000 pessoas, o que equivale a menos de $7 \%$ do total de pessoas destas classes.

\begin{tabular}{|c|c|c|c|c|c|c|c|c|}
\hline & 2005 & 2006 & 2007 & 2008 & 2009 & 2010 & 2011 \\
\hline $\mathrm{A}$ & 54 & 57 & 81 & 76 & 78 & 64 & 83 \\
\hline $\mathrm{B}$ & 40 & 33 & 54 & 54 & 57 & 50 & 59 \\
\hline $\mathrm{C}$ & 14 & 13 & 26 & 25 & 27 & 22 & 28 \\
\hline $\mathrm{D} / \mathrm{E}$ & 4 & 2 & 7 & 7 & 6 & 4 & 6 \\
\hline
\end{tabular}

Tabela 6: Série histórica 2005-2011. Proporção de usuários de governo eletrônico ${ }^{24}$ por ano, segundo a classe social - Percentual sobre o total da população. Fonte: Elaboração própria com dados selecionados da pesquisa TIC-Domicílios (< $\underline{\text { http://www.cetic.br/publicacoes/>) }}$

21 Indivíduos acima de 16 anos que utilizaram o governo eletrônico nos 12 meses anteriores à data da entrevista.

22 Conforme já observado na nota $\mathrm{n}^{\mathrm{o}}$ 10, em 2012 o CETIC.Br apresentou somente a percentagem de usuários de internet que utilizaram o governo eletrônico e não a percentagem de pessoas em geral que utilizaram o governo eletrônico. Ou seja, a proporção foi feita sobre o número de usuários de internet e não sobre a população.

23 Estimativa divulgada pelo IBGE em agosto/2012. Cf. http://www.brasil.gov.br/governo/2012/08/populacao-brasileiraatinge-194-milhoes

24 Indivíduos acima de 16 anos que utilizaram o governo eletrônico nos 12 meses anteriores à data da entrevista. 


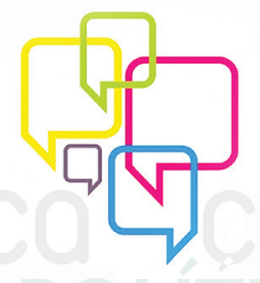

açãô Imidiática

N. 6 | Ano 2013

Universidade Federal do Paraná | Programa de Pós-Graduação em Comunicação

\begin{tabular}{|c|c|c|c|}
\hline \multicolumn{5}{|c|}{ Total: 65} \\
\hline \multicolumn{5}{|c|}{ Escolaridade } \\
\hline \multicolumn{5}{|c|}{ Urbana: 66} & Rural: 50 \\
\hline Fundamental: 45 & Classe social & Superior: 85 \\
\hline \multicolumn{5}{|c|}{ B: 74} & C: 56 & D/E: 48 \\
\hline A: 88 & \multicolumn{2}{c}{} \\
\hline
\end{tabular}

Tabela 7: 2012. Proporção de usuários de internet que utilizaram governo eletrônico nos últimos 12 meses, por área (urbana/rural), grau de escolaridade e classe social - Percentual sobre o número de usuários de internet. Fonte: Elaboração própria, com dados selecionados da pesquisa TIC-Domicílios de 2012 (< $\underline{\text { http://www.cetic.br/ }}$ publicacoes/2012/tic-domicilios-2012.pdf $>$ )

Chama a atenção nos dados de 2012, em primeiro lugar, o percentual de uso de governos eletrônicos no Brasil: apenas 65\% do total de usuários de internet acessou um e-gov nos 12 meses que antecederam a entrevista da pesquisa. Neste contexto, ganha pertinência a avaliação feita por Duarte $(2009$, p. 67) de que as barreiras na comunicação pública atualmente "não são a falta de instrumentos ou de informação, mas a dificuldade em ajudar o interessado a descobrir que ela existe, onde está, como acessá-la e como utilizá-la para aumentar seu conhecimento e capacidade de agir".

Mais preocupante, porém, é o fato de menos da metade dos usuários de internet pertencentes às classes $\mathrm{D} / \mathrm{E}$ acessar governo eletrônica, enquanto o percentual da classe A fica em 90\%. Da mesma forma, apenas 45\% dos usuários que tem ensino fundamental usam e-gov, sendo de $85 \%$ o percentual dos que tem nível superior. Ou seja, como observa Duarte a respeito dos instrumentos de comunicação pública: “O problema é que as pessoas que mais precisam de informação em geral são as que têm menos acesso aos mecanismos de transmissão e orientação ou possuem mais dificuldade de compreensão de seu significado" (DUARTE, 2009, p. 67).

\section{Observações finais}

Ao determinar a "utilização de meios de comunicação viabilizados pela tecnologia da informação" como procedimento na divulgação das informações de interesse público, a Lei de Acesso à Informação Pública (LEI No 12.527 ..., 2011) pressupõe a inclusão digital de toda a população. Ao definir como "dado aberto" todos os "dados públicos representados em meio digital, estruturados em formato aberto, processáveis por máquina, referenciados na rede mundial de computadores e disponibilizados sob licença aberta que permita sua livre utilização, consumo ou cruzamento", na Instrução Normativa que "Institui a Infraestrutura Nacional de Dados Abertos - INDA” (INSTRUÇÃO ..., 2012), o Plano de Ação Nacional sobre Governo Aberto também pressupõe a inclusão digital de toda a população. 


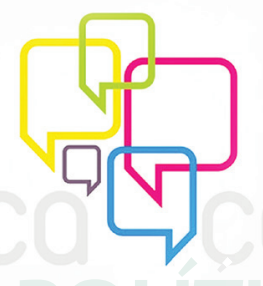

\section{açãô midiática}

N. 6 | Ano 2013

\section{Universidade Federal do Paraná I Programa de Pós-Graduação em Comunicação}

Mais do que estes dois exemplos, porém, tanto a criação quanto toda a trajetória de desenvolvimento do governo eletrônico no Brasil, como demonstrado neste artigo, estão diretamente ligadas à garantia da universalização do acesso, pois o e-gov, além de conter informações e serviços oferecidos exclusivamente online, também se apresenta como realização da eficácia, disponibilidade (a qualquer hora em qualquer lugar), transparência, acessibilidade e abertura, entre outros diferenciais que, mantidos como privilégios das classes hegemônicas, colocam em questão a própria constituição democrática do país.

\section{Referências bibliográficas}

BAGGIO, Rodrigo. Entrevista a Marcelo Medeiros, em 22/03/2005, publicada no Observatório da Imprensa, edição $\mathrm{n}^{0}$ 321. Disponível em: <http:/www.observatoriodaimprensa.com.br/ news/imprimir/1007>. Acesso em: 15 Out. 2013.

BARROS, Fábio. Lei de Informática: Abinee fecha acordo com a Receita Federal. Convergência Digital, 02/04/2013. Disponível em: < http://convergenciadigital.uol.com.br/cgi/cgilua.exe/sys/ start.htm?infoid=33383\&sid=7\#.Un7Fi8UVY0j>. Acesso em: 17 Jul. 2013.

BECKER, Maria Lúcia. Inclusão digital e cidadania: as possibilidades e ilusões da "solução" tecnológica. Ponta Grossa: Ed. UEPG, 2009.

BERBERT, Lúcia.Anatelarrecada R \$48,1 bi desde sua criação em 1997. TeleSíntese, 17/01/2011. Disponível em: <http://www.telesintese.com.br/index.php/plantao/77-plantao-2011/plantao2011/8739-anatel-arrecada-r-481-bi-desde-sua-criacao-em-1997>. Acesso em: 11 jul. 2013.

DUARTE, Jorge. Instrumentos de comunicação pública. In: DUARTE, Jorge (Org.). Comunicação Pública: Estado, Mercado, Sociedade e Interesse Público. São Paulo: Atlas, 2009, p. 59-71.

HAJE, Lara. Deputados cobram uso do Fust para ampliação do acesso à banda larga no país. Câmara Notícias, 24/04/2013. Disponível em: <http:/www2.camara.leg.br/camaranoticias/ noticias/CIENCIA-E-TECNOLOGIA/440981-DEPUTADOS-COBRAM-USO-DO-FUSTPARA-AMPLIACAO-DO-ACESSO-A-BANDA-LARGA-NO-PAIS.html>. Acesso em: 26 abr. 2013.

LEMOS, André (Org.). Cidade digital: portais, inclusão e redes no Brasil. Salvador: EDUFBA: 2007.

MARTINS, Wolney Mendes. Classificação das atividades de governo eletrônico e as oportunidades de aperfeiçoamento das relações sociedade/Estado. In: FERRER, Florência e SANTOS, Paula (Orgs.). e-government: o governo eletrônico no Brasil. São Paulo: Saraiva, 2004, p. 16-24.

QUEIROZ, Cláudia Santa Rita de. O Fundo de Universalização dos Serviços de 


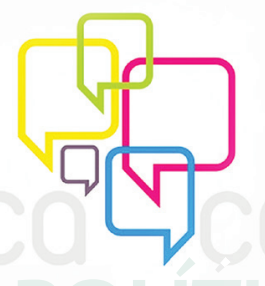

açãô İmidiática

Universidade Federal do Paraná | Programa de Pós-Graduação em Comunicação

Telecomunicações - FUST. Brasília: Universidade de Brasília, 2010. Curso de Especialização em Orçamento e Políticas Públicas [Monografia]. Disponível em: < $\underline{\text { http://www.ceag.unb.br/ }}$ ceag/public/arquivos/biblioteca/07b9698c7f1b303cc84a35a43de96d16.pdf $>$. Acesso em: 14 jul. 2013.

TOCARNIA, Mariana. Maioria dos alunos de ensino médio nas escolas públicas tem acesso a biblioteca e internet, diz MEC. Agência Brasil, 2013. Disponível em: $<$ http://agenciabrasil. ebc.com.br/noticia/2013-06-05/maioria-dos-alunos-de-ensino-medio-nas-escolas-publicastem-acesso-biblioteca-e-internet-diz-mec>. Acesso em: 06 jun. 2013.

\section{Documentos eletrônicos online}

2 ANOS DE GOVERNO ELETRÔNICO: balanço de realizações e desafios futuros. Brasília: ComitêExecutivo do Governo Eletrônico, 2002. Disponível em: $<$ http://www.governoeletronico. gov.br/anexos/E15 90balanco_2anos_egov.pdf>. Acesso em: 10 Fev. 2011.

CETELEM BGN. Observador Brasil 2012. Disponível em: <http://www.cetelem.com.br/ portal/Sobre_Cetelem/Observador.shtm>. Acesso em: 9 mar. 2013.

CETIC.Br. TIC-Domicílios de 2012. Disponível em: < http://www.cetic.br/publicacoes/2012/ tic-domicilios-2012.pdf>. Acesso em: 3 ago. 2012.

DECRETO No 3.624 de 5 de outubro de 2000. Disponível em: < $\underline{\text { http://www.planalto.gov.br/ }}$ ccivil 03/decreto/d3624.htm>. Acesso em: 26 out. 2013.

GESAC. Relatório 2009. Brasília: DESID/STE/MC, 2010. Disponível em: < $\underline{\text { http://www.gesac. }}$ gov.br/images/avaliacao/Relatrio __Avaliao.pdf>. Acesso em: 11 fev. 2011.

INSTRUÇÃO NORMATIVA № 4, 12 de abril de 2012. Institui a Infraestrutura Nacional de Dados Abertos - INDA. Disponível em: < $<$ http://dados.gov.br/instrucao-normativa-da-inda/ $>$. Acesso em: 10 nov. 2013.

LEI N ${ }^{\circ}$ 12.527, de 18 DE NOVEMBRO DE 2011. Lei de Acesso à Informação Pública. Disponível em: <http://www.presidencia.gov.br/ccivil 03/_Ato2011-2014/2011/Lei/L12527. $\underline{\mathrm{htm}}>$. Acesso em: 10 nov. 2013.

KHAIR, Amir Antônio. Lei de Responsabilidade Fiscal: guia de orientação para as prefeituras. Brasília: Ministério do Planejamento, Orçamento e Gestão; BNDES, 2000.

PROPOSTA DE POLÍTICA DE GOVERNO ELETRÔNICO PARA O PODER EXECUTIVO FEDERAL. Brasília, 2000. Disponível em: <http:/www.governoeletronico.gov.br/anexos/ E15 90proposta_de_politica_de_governo eletronico.pdf $>$. Acesso em: 14 ago. 2013.

SOCIEDADE DA INFORMAÇÃO NO BRASIL - LIVRO VERDE. Disponível em: $<\underline{\text { http:// }}$ www.miniwebcursos.com.br/cursos antigos/conhecendo_ead/botoes/modulos/modulo_4/ 

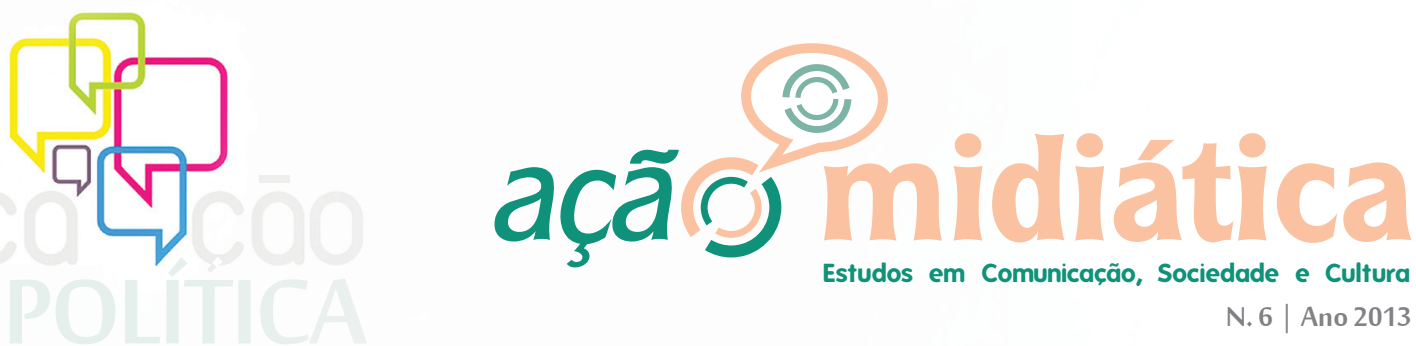

Universidade Federal do Paraná | Programa de Pós-Graduação em Comunicação

Artigos/livroverde.pdf> . Acesso em: 14. Ago. 2013.

(Footnotes)

1 O CETIC.Br não traz dados do total da população no ano de 2007, divulga apenas os números da população urbana (Cf. http://op.ceptro.br/cgi-bin/cetic/tic-2007.pdf). Assim, optou-se aqui por trabalhar com os dados da população total, desconsiderando, portanto, os números de 2007, dentro do entendimento de que a padronização da tabela com todos os dados da população urbana seria um falseamento grosseiro da realidade, dada a diferença das situações urbana e rural, como pode ser visto na Tabela 1. 